University of Nebraska - Lincoln DigitalCommons@University of Nebraska - Lincoln

2014

\title{
Analysis of training initiatives undertaken for professional development of library professionals in Pakistan
}

Ahsan Ullah

Govt Degree College Pindi Bhattain Punjab Pakistan, ahsanullah_libr@yahoo.com

Follow this and additional works at: http://digitalcommons.unl.edu/libphilprac

Part of the Library and Information Science Commons

Ullah, Ahsan, "Analysis of training initiatives undertaken for professional development of library professionals in Pakistan" (2014).

Library Philosophy and Practice (e-journal). 1156.

http://digitalcommons.unl.edu/libphilprac/1156 


\section{Analysis of training initiatives undertaken for professional development of library professionals in Pakistan}

\section{Introduction}

Information explosion means huge growth in information and emergence of information age, which is characterized by the ability of individuals to have instant access to information and to transfer it freely. Information has emerged as important source of education, teaching, research and development, and has immensely affected the modern library and information centers. The convergence of information and communication media such as telecommunications, broadcasting, communication and print media is another important factor reshaping the future of libraries. It has made it possible to acquire and store digitized versions of many different kinds of learning content such as texts, pictures, audios and videos. Growth of electronic resources due to emergence of processes like digitization and automation has transformed the library activities and has also triggered the need for professional development of library professionals. Emerging use of cloud computing in libraries has made it possible for libraries to manage their contents at remote servers. Open source software spread has made the content management very cheap and simple and also made it possible for libraries to automate their resources without purchasing costly databases. Access to information, with the help of telecommunication infrastructure is one of the underlying factors of this transformation process.

Moreover, teaching and learning environment has been changed completely with the introduction of web 2.0 tools and has connected the people across the globe irrespective of their physical location. Exchange of information in collaborative environment with library users is made possible with the help of web 2.0 tools like blogs, instant messaging, Facebook, Twitter and wikis. Information has become ubiquitous and it has overcome the barriers of space and time. Now information can be reached with mobile tools like iPod, mobile phone etc. These technologies have connected the library professionals all around the world into social networks for serving library users more diligently. According to Ullah, Ameen and Bakhtar (2011) information and communication technology has not only transformed library and information services but also "transformed the information seeking behaviour of library users and they demand and expect the services and programmes accordingly". 
Continuing technological advances require more professional development of library professionals to grasp basic as well as modern skills and knowledge for using these technologies in libraries. Professional development seems to be the crucial component for information management that will inculcate the ability to apply innovative technologies effectively in libraries for the completion of tasks. Training of professionals can enhance and activate their knowledge in an integrated manner to fulfill users' needs for information. Professional development is the way to enhance the skills and competencies needed for performing the library tasks more skillfully. It enables the library professionals to upgrade their knowledge according to the needs of the hour. Staff development initiatives are very important tools for developing library professionals to face current and future challenges (Khan and Rafiq, 2013). The role and need for training initiatives initiated for professional development of library professionals has increased in recent years. The above cited changing library environment has increased the need for investigating training initiatives initiated by different organizations for the continuing professional development of library professionals to cope with the challenges of information age.

Initiative is defined as the "power or opportunity to do something before others do it [and] plan or program that is intended to solve a problem". Training initiatives are defined as the programs that are designed to equip library professionals with requisite skills needed for managing a library. Training initiatives may also be defined as the specific actions used to enhance the skills of library professionals for maximizing productivity in libraries. Training initiatives may be divided into different categories such as workshops and seminars. Workshop is defined as a "brief intensive educational program for a relatively small group of people that focuses especially on techniques and skills in a particular field."While seminar is referred to as a meeting in which you receive information on and training in a particular subject. Modern information and communication technology empowers the trainer or organization to conduct the training in face to face or online environment. Some training initiatives are restricted for only specific group of librarians while others are conducted for all professionals irrespective of their organizations.

Background knowledge of the LIS profession and basic skills for organizing and retrieving information and information sources are important needs of library professionals and it need to be reinforced with training initiatives. The best outcomes can be expected from individuals who have relevant knowledge of latest technology and understands basic teaching methodology and 
techniques being used in educational environment. Libraries are referred to as information commons as they are integrated centers for research, teaching and learning and possess technology and information-rich environments. Bhatti, R. (2013) advocated that "it is also very necessary for the library staff to keep pace with the change of technology. As the technology changes the sources of information are also changed. New sources and channels particularly the world wide websites have brought new challenges and issues". Professional development of library professional should be an ongoing process rather than a finite process to enable library professionals to adapt to innovative technologies and techniques necessary for library growth. The professional development starts with initial education at a graduate program in library science in universities and continues throughout the professional life of individuals by enhancing their skills through participating in seminars and workshops organized by different organizations at national and international levels.

Training initiative for workforce is an important instrument used for getting optimal performance so, trained, dynamic and enterprising library professionals are necessary for increasing the output of libraries and satisfying user needs. Building of skills of library professionals is very important to keep pace with the rapid change emerging through growth of information media. It is most important for library professional to have the requisite skills needed to supervise, operate and execute quality library operations and fulfilling the research needs of library users. That is, if training is not provided to library professionals relating to wide areas of library administration, they will not be able to cope with the changing information paradigm. Robinson and Glosiene (2007) have categorized the content of training initiatives conducted by Training Centre Network initiative into five categories such as core courses (reader services, classification, cataloguing and resource description), transition topics (marketing and promotion of library services), ephemeral topics (grant writing, library management software), local topics (psychology of users, LIS culture) and topics related to ICT use.

The increased availability and importance of training programs have necessitated a need to "continually monitor and evaluate such programs"( Faoite, , Henry, Johnston and Sijde, 2004) initiated for library professionals in Pakistan. This study will not only identify different areas such as web 2.0, research skills, and management skills etc in which training is offered to professionals in Pakistan but also measure the geographical distribution of these training initiatives. This will ultimately lead to the identification of weak and strong areas in which 
training is provided to library professionals. Locations of the training opportunities are also investigated to understand the focus of training programs and this study will also indicate the neglected geographical areas that got less attention of trainers. Under the influence of these developments this study has investigated the training initiatives undertaken for library professionals by different organizations in Pakistan to increase competence of librarians in Pakistan to make them responsive to needs of library users and aggressively fulfill the needs of digital age. Different studies in Pakistan were carried out to understand the training needs of library professionals but few studies have been undertaken to evaluate the nature of training initiatives that are made available to library professionals in Pakistan. The present study will fill this gap by eliciting the trends for providing training opportunities to library professionals.

\section{Literature Review}

A lot of international literature is available about training initiatives for professional development of library professionals at international level. A process was undertaken by Colorado State University libraries faculty task force to address concerns regarding training opportunities to library professionals working in their libraries. They collected and examined

feedback from faculty librarians and recommended possible training initiatives to library administration and council (Feldmann, Level \& Liu ,2013). Bresnahan and Johnson (2013) conducted a survey to determine local training needs about scholarly communication and research data management of liaison librarians and concluded that training about research data topic should be prioritized. A sound structure for in-house training of library professionals in times of economic recession is necessary for developing their skills. Need assessment is the necessary instrument for constructing a training program to train the human resources competitively (Crumpton, 2011).

Adam (2009) has conducted a study to determine the approach adopted by the staff development committee to reinvigorate personal and personal development of library staff. He developed a skill and attribute matrix which mapped the current and future courses for the creation of program for professional development of library professionals. Robinson and Glosiene (2007) have conducted a study of network of training centers for its role for continuing development of library professionals and found that this network of training centers remain successful for enhancing competencies of library professionals working in these centers. Different areas of 
library operations such as ICT skills, networking skills, copyright and library licensing of digital material and library systems need professional training of library professionals to perform these operations optimally (Pedersen 2007). Oduwole and Sho (2007) have reported an international training program at University of Illinois for connecting librarians all across the world and found this program helpful for professionals to exchange information about practices in librarianship. Robinson, et al. (2005) has identified a set of skills and competences needs for library staff and advocated that library professionals should possess strong information literacy skills and become active lifelong learners to come up to the expectations of the users. He further prescribed that elearning approach along with other methods to be adopted for enhancing the skills of library professionals.

Homan, Foundation and McGowan (2002) asserted that due to introduction of information technology in the health care environment, health care professionals need to redefine their approaches of training. He recommended partnership of Medical Library Association with universities for offering certified programs having demonstrated competences in key areas such as technology. Matthews and Thebridge (2001) have assessed the training needs of library professionals for preserving human knowledge for future generations. They reviewed the training initiatives about preservation of library material in UK and abroad and suggested sector wide professional development and training initiatives. Todd and Tedd (2000) have described two training initiatives including the National Grid for Learning and the University for Industry for lifelong development of library professionals in UK. They further highlighted the role of public libraries for providing information and communication technology courses to lifelong learners. Technological development, organizational development and focus on end users are major influences that have implication for the training initiatives meant to meet the emerging and future needs of professionals (Lawes, 1996).

Many studies are available in national literature that has analyzed the training initiatives undertaken for professional development of library professionals in Pakistan. Some studies have thrown light about the training initiative undertaken for professional development of librarians in Pakistan and many other studies have elaborated the training needs and avenues of training available for library professionals in Pakistan. Khan, Muhammad Arif', Idrees \& Khan, Muhammad Mudassir (2013) conducted a study to judge and evaluate the professional 
development initiatives initiated by Pakistan Academy of Rural Development for the training of their professionals. They asserted that practical involvement, field visits and specialized training sessions for employees are traditional elements that need to be considered for the capacity building of library staff. Different initiatives were started to enhance skills in different areas such as LIMS, WINISIS, EDDC, Web Dewey, Z 39.5, open source software and browsing online databases. They found that staff of academy has benefited personally and professionally from these development opportunities.

Personal quest, conferences and workshops, reading professional literature are important ways adopted by library professionals of Punjab University libraries to enhance their professional competence. Future interest of these professionals indicate their priorities of different areas such as digital library, information retrieval, databases, digital cataloguing and digital reference (Anwar, Uzma \& Wariach, Nosheen Fatima, 2013 ). Library professionals have expressed that management and leadership skills, information technology and communication skills are the priority areas that need to be covered while designing in-service training initiatives for library professionals in Pakistan. They found that $80 \%$ preferred practical work (courses/workshops) and only $20 \%$ respondents emphasized for lectures and exercises (Khan, \& Rafiq 2013).

Training opportunities available for medical librarians in Pakistan are not enough for fulfilling the professional needs of medical librarians. Respondents stated that the skills such as use of ICT, integrated library software, subject headings, classification schemes, refrencing styles, ability to coordinate and assessing information needs of users are necessary for performing professional activities (Ullah, Ameen \& Bakhtar, S. 2010). Jabeen (2010) investigated the training avenues available to library professionals in Pakistan and suggested some measures to be taken for its improvement. Mahmood (1998) has described 105 events of training courses, conferences, workshops, seminars, lectures and demonstrations from 1988 to 1996 conducted for the continuing education of larger group of qualified librarians relating to information technology with its duration, location, date, year and name of sponsors. Different areas such as library automation, databases (CDS/ISIS, LAMP, INMAGIC, Scimate), computer applications, computer basics email and internet etc were covered in these events conducted for continuing education. More than 80 events were training courses and workshops and ten events were conferences and seminars with only five lectures. 


\section{Objectives}

The main objectives of this study are as under:

1. To explore the mode and duration of training initiatives undertaken in different areas of library and information science in the last five years for professional development of library professionals in Pakistan.

2. To examine venues (physical location of training) of training initiatives made available to library professional in Pakistan to identify the focus of training activities.

3. To explore the nature of subject areas and fields of training activities for identifying gaps relating to important fields.

\section{Methodology}

Social networking software such as mailing groups, mailing lists, internet discussion groups and listserv appeared on the scene in 1990s but in Pakistan online mailing groups of library professionals were launched in 2000s. Siddique, \& Mahmood (2009), asserted that Pakistan Library Automation Group (PakLAG), an online group of volunteer LIS professionals, "provides an opportunity to its members for instant dissemination of library-related information and discussion on different issues". It is a widely used online group of library professionals in Pakistan that was established on 19 December 2000 to provide forum for library professionals to share information about library trends, library automation and information technology. It was established as public group and its current membership is 4374. Another important online mailing group that has reasonable membership is the Pakistan Library Cooperation Group (LIBCOOP) that was initiated on 20 August 2004 as restricted group with current membership of 936 library professionals for sharing information and experiences about library projects. All the important information and issues about library developments including information about training initiatives for maximizing the participation of professionals and reports about these initiatives are shared by library professionals on these online mailing groups. Even if the training initiative for library professionals is restricted only to a particular group of library professionals, its results, achievements and pictures are shared with the professionals through these groups.

In this study, two widely used groups were selected for retrieving messages posted on these groups about training initiatives. The messages were searched from these groups from year January, 2009 to 31 December 2013 on yearly basis and all the relevant messages were copied and pasted in a word document. Afterwards these messages were perused online again for 
checking of duplication and extracting contents of these messages. The content analysis methodology was applied and data was coded and entered in different columns in Microsoft Excel from online yahoo group training initiatives and if any duplication was identified from the titles from years and other columns then the message was deleted. Quantitative data collected from the messages of yahoo group was analyzed with the help of simple statistical techniques while the subject areas of the training initiatives were determined from the titles, sub titles and content details of the training initiatives by grouping it into different categories. Similarities in the data were identified by using assort and filter option of Microsoft Excel.

\section{Limitations of the study}

The study is limited to the training initiatives communicated via yahoo mailing groups of library professionals in Pakistan. Researcher believes that most of the trainings conducted in Pakistan are shared on these groups as researcher also participated in some workshops from the information shared on these groups but still there is possibility that some initiatives are not reported on these groups. This study also excludes all the training initiatives undertaken before 2009 and after 2013. Furthermore some initiatives reported on these groups for registration of librarians may not have been conducted. Similarly some training initiatives that were conducted locally may not be published on the groups.

\section{Data Analysis}

\section{Frequency of training initiative conducted from 2009 to 2013}

The following table indicates steady and marginal growth in the training initiatives in different years from 2009 to 2013. First year i.e. 2009 got less number (13\%) of training initiatives while in all other years more than $20 \%$ trainings were conducted.

Table 1: Frequency of training initiative conducted from 2009 to 2013

\begin{tabular}{|l|l|l|l|}
\hline Sr. No. & Training on yearly bases & Frequency & Percentage \\
\hline 1 & 2009 & 13 & 13 \\
\hline 2 & 2010 & 19 & 20 \\
\hline 3 & 2011 & 20 & 21 \\
\hline 4 & 2012 & 21 & 22 \\
\hline 5 & 2013 & 23 & 24 \\
\hline & Total & $\mathbf{9 6}$ & $\mathbf{1 0 0}$ \\
\hline
\end{tabular}

\section{Frequency of duration of training}


Major portion of training were conducted for few days only as more than $57 \%$ training were conducted for one day and $24 \%$ training were conducted for two days. This may be due to finances involved in the arrangement for residence of employees. Time constraints and institutional hindrances may also have hampered the conduct of long training sessions. Fewer training subjects may also have contributed towards short durations as these may require short time. Long duration trainings include many subjects for example one seven days training include RDA, social media, LIMS, EDDC and referencing with Endnote.

Table 2: Frequency of duration of training

\begin{tabular}{|l|l|l|l|}
\hline S. N. & Duration of training & Frequency & Percentage \\
\hline 1 & One day & 55 & 57 \\
\hline 2 & Two days & 23 & 24 \\
\hline 3 & Three days & 6 & 6 \\
\hline 4 & Five days duration & 10 & 11 \\
\hline 5 & Seven days duration & 2 & 2 \\
\hline & Total & $\mathbf{9 6}$ & $\mathbf{1 0 0}$ \\
\hline
\end{tabular}

\section{Frequency of training on the basis of mode}

In spite of development in communication and information technology most (88\%) training workshops were conducted in face to face mode. Two workshops of international scope were purely online and most recent workshops offered on citation management and qualitative research using NVIVO were offered in both face to face and online modules for the facilitation of professionals.

Table 4: Frequency of training on the basis of mode

\begin{tabular}{|l|l|l|l|}
\hline Sr. No. & Mode of training & Frequency & Percentage \\
\hline 1 & Face to face & 88 & 92 \\
\hline 2 & Online & 2 & 2 \\
\hline 3 & Both face to face and online & 6 & 6 \\
\hline & Total & $\mathbf{9 6}$ & $\mathbf{1 0 0}$ \\
\hline
\end{tabular}

\section{Venues of Training}


Nearly $40 \%$ training workshops were conducted at university premises including auditoriums, university departments. Library Science departments have contributed only $10 \%$ for offering their facilities and cooperation for the conduct of training workshops at their premises. Almost $41 \%$ trainings were conducted at different libraries. University libraries have contributed more than other libraries followed of special libraries established with different research institutions, centers and academies. Public libraries have participated in only $8 \%$ initiatives while national library and college libraries have offered their premises for only one and two trainings respectively.

\section{Table 5: Venues of Training}

\begin{tabular}{|l|l|l|l|}
\hline $\begin{array}{l}\text { Sr. } \\
\text { No. }\end{array}$ & Venues of training & Frequency & Percentage \\
\hline 1 & University Auditoriums & 25 & 26 \\
\hline 1 & University departments (Library Science) & 10 & 11 \\
\hline 1 & University departments (Others) & 8 & 8.3 \\
\hline 2 & Research Institutions & 8 & 8 \\
\hline 3 & University Library & 20 & 21 \\
\hline 3 & Research institution/center library & 12 & 13 \\
\hline 3 & Public Library & 8 & 8 \\
\hline 3 & National Library & 1 & 1 \\
\hline 4 & College Libraries & 2 & 2 \\
\hline 4 & Motel & 2 & 2 \\
\hline & Total & $\mathbf{9 6}$ & $\mathbf{1 0 0}$ \\
\hline
\end{tabular}

\section{Frequency of training in Islamabad and provinces}

Nearly $45 \%$ of the training activities were organized in Punjab followed by Islamabad with $28 \%$. Reasonable training activities were organized in Sindh and Khyber Pakhtunkhwa (KP).

Baluchistan was the ignored province as compared with other provinces of the country as no training activity was conducted in this province.

Table 6: Frequency of training in Federal territory (Islamabad) and provinces 


\begin{tabular}{|l|l|l|l|}
\hline Sr. No. & Province wise training & Frequency & Percentage \\
\hline 1 & Islamabad (Federal Capital) & 27 & 28 \\
\hline 2 & Punjab & 43 & 45 \\
\hline 3 & Sindh & 13 & 13.50 \\
\hline 4 & Khyber Pakhtunkhwa & 13 & 13.50 \\
\hline 5 & Baluchistan & 0 & 0 \\
\hline & Total & $\mathbf{9 6}$ & $\mathbf{1 0 0}$ \\
\hline
\end{tabular}

\section{Frequency of training in different cities}

Lahore remained at the top for hosting $32 \%$ of training initiatives and followed by federal capital with $28 \%$ training initiatives. Capital of Sindh (Karachi) and KP (Peshawar) have also hosted reasonable number of training workshops. All other cities have hosted only one, two or three workshops.

Table 7: Frequency of training in different cities

\begin{tabular}{|l|l|l|l|}
\hline Sr. No. & Sponsor of training & Frequency & Percentage \\
\hline 1 & Lahore & 31 & 32 \\
\hline 2 & Islamabad & 27 & 28 \\
\hline 3 & Karachi & 13 & 14 \\
\hline 4 & Peshawar & 11 & 12 \\
\hline 5 & Bahawalpur & 3 & 03 \\
\hline 7 & Sargodha & 3 & 03 \\
\hline 8 & Fateh Jang Jhelum & 2 & 02 \\
\hline 9 & Faisalabad & 2 & 02 \\
\hline 10 & Abbotabad & 1 & 01 \\
\hline 11 & Multan & 1 & 01 \\
\hline 12 & Muzaffarabad & 1 & 01 \\
\hline 13 & Gujrat & 1 & 01 \\
\hline & Total & $\mathbf{9 6}$ & $\mathbf{1 0 0}$ \\
\hline
\end{tabular}

Frequency of training on the basis of field of training 
Majority of training initiatives were conducted on Endnote and research skills, library automation and library management skills. In category of Library automation most of the training workshops provided training on open source software such as Koha, DSpace and Greenstone Digital Library software and no training is conducted on proprietary software and cloud computing. Web searching skills, Web 2.0, e-library, MARC, digital asset management and social tagging are other key areas of training initiatives. Information retrieval and digital reference were the priority areas for training (Anwar, Uzma \& Wariach, Nosheen Fatima, 2013) as expressed by librarians but these subjects are still missing in these initiatives.

Table 8: Frequency of training on the basis of field of training

\begin{tabular}{|l|l|l|}
\hline $\begin{array}{l}\text { Sr. } \\
\text { No. }\end{array}$ & Field of training & Frequency \\
\hline 1 & Calibre E-book management system & 1 \\
\hline 2 & Capacity building of college/School librarians & 2 \\
\hline 3 & Competencies for information professionals (Koha, DSpace, traits) & 2 \\
\hline 4 & Core techniques in libraries and information management & 1 \\
\hline 5 & DDC 23 edition & 1 \\
\hline 6 & Digital librarianship & 1 \\
\hline 7 & Double your reading speed & 1 \\
\hline 8 & E-library USA database searching & 1 \\
\hline 9 & Emerging technologies in libraries: New challenges for LIS professionals & 2 \\
\hline 10 & Literature review (Endnote, APA, Bibliography, References) & 8 \\
\hline 11 & Etiquettes, Mannering and customer care & 1 \\
\hline 12 & Health and medical research information & 1 \\
\hline 13 & Hunt a job with Shafiq Rana & 1 \\
\hline 14 & ICT Role of ICT in library management (Koha, Dspace, OPACS, etc) & 7 \\
\hline 15 & Information literacy skills(APA, Endnote, Plagiarism) & 3 \\
\hline 16 & Information management techniques (RDA, Social media, Referencing) & 2 \\
\hline 27 & Koha & 7 \\
\hline 18 & Koha and Dspace & 3 \\
\hline 19 & Koha, Dspace and Library World & 1 \\
\hline 20 & Koha and GSDL & 1 \\
\hline 21 & Leadership, high goals and public speaking & 2 \\
\hline 22 & Library 2.0 & 1 \\
\hline 23 & Library automation and management (LIMS, EDDC, OPAC,) & 3 \\
\hline 24 & Library skills development (MARC, ILS, information retrieval) & 2 \\
\hline 25 & LIMS and digital library & 1 \\
\hline 26 & LIMS and PakLAG and OPAC & 1 \\
\hline 27 & LIMS/EDDC & 1 \\
\hline 28 & Managing academic theses for Mphil/PhD & 1 \\
\hline 29 & Marketing library products and services & 1 \\
\hline 30 & Mastering dissertation theses paper writing (Endnote/SPSS) & 1 \\
\hline & & \\
\hline
\end{tabular}




\begin{tabular}{|l|l|l|}
\hline 31 & Modern library practices in library environment (ethics, GSDL, Tools) & 2 \\
\hline 32 & Open source ILS (Dspace, Wordpress, Joomla, Limesurvey) & 3 \\
\hline 33 & Personal Knowledge management & 1 \\
\hline 34 & Qualitative research with NVIVO, AMOS etc & 6 \\
\hline 35 & RDA & 1 \\
\hline 36 & Reading research activity method & 1 \\
\hline 37 & Re-visioning school libraries time in for now & 1 \\
\hline 38 & Romanization and Transliteration (MARC) & 1 \\
\hline 39 & Social tagging and library practices for knowledge practices & 1 \\
\hline 40 & SPSS version 17 & 1 \\
\hline 41 & Survey design and sampling techniques & 1 \\
\hline 42 & Survival in digital age: Challenges for LIS professionals & 1 \\
\hline 43 & Transforming library technology infrastructure & 1 \\
\hline 44 & Use of online resources (HEC DL, search engines) & 1 \\
\hline 45 & Use of HEC digital library and online searching techniques & 2 \\
\hline 46 & Use of information and electronic resources & 3 \\
\hline 47 & Web 2.0 technologies usage and application & 2 \\
\hline 48 & Web information retrieval: tools and techniques & 1 \\
\hline 49 & Web Searching skills & 3 \\
\hline 50 & Web Searching skills and research ethics, and citation management & 1 \\
\hline 51 & Web searching, documentation process and file management & 1 \\
\hline & Total & $\mathbf{9 6}$ \\
\hline
\end{tabular}

\section{Findings}

This study found that most of the trainings were held at Punjab and Islamabad. Reasonable trainings were conducted in Sindh and KP but no training has ever been conducted in Baluchistan. Mode of training was face to face in majority of training activities but in recent years trainings were conducted in both online and face to face modes.

The frequency of training initiatives reveals that library automation, role of ICT in libraries, qualitative research, research skills, open source software, web searching skills and use of digital resources are key areas of training initiatives in Pakistan. Library management skills are other important areas that got attention of trainers and many workshops were conducted on these subjects. Training areas that have attracted major chunk of training initiatives include automation of library operations, research skill and relevant software and library management skills. Other areas which have got representation in these modules include e-library, digital asset management, and social tagging etc. 


\section{Conclusion and Recommendations}

Information and related phenomena gain unprecedented significance in the present age of information explosion. Information and communication technologies are changing at very fast speed and more sophisticated equipments and facilities are being developed very regularly that are useful for libraries so it is essential for library professionals to update their skills to handle and operate these technologies efficiently. Ershova (2002) considers library as the most important part of the information society due to its immense information resources. Library need to be embedded in this environment for providing efficient services to users. Training of library professionals is an important aspect to make library professionals more responsive to the needs of information era.

Data analysis has revealed that most of the training initiatives were about database, software, digitization and automation activities. Moreover, these initiatives were substantiated by library management skills and research skills for strengthening the management and research skills. Professional training is very important instrument for the promotion of skills of library professionals about different operations of library. Professional training reinforces the knowledge of their subjects and operational competence among librarians and enhances their ability to carry out library work more effectively and efficiently. Following proposals are suggested for making these training initiatives more effective:

- Underdeveloped areas of the country particularly Baluchistan should get more training in near future to make amends for the past negligence.

- Online mode for the conduct of training may also be promoted to make use of advanced information and communication technology.

- Public Libraries and College Libraries should be encouraged to come forward in take part in the professional development of their personnel.

- It is highly desirable for libraries and their parent institutions to have a continuing professional development plan for the library professional as part of the library development plan. Library professionals may be encouraged to participate in training activities through incentives such as salary increases or credits for promotion. Specific campaigns or strategic policies may also be framed for raising their participation in training activities. 
- Online yahoo groups are performing excellent role for providing awareness to library professionals but a special agency need to be created to do this job more aggressively. A council should be formed for informing library professionals about initiatives undertaken for their professional development. (Anwar, Uzma \& Wariach, 2013 )

- Social media tools, proprietary software and cloud computing are the key areas that also need attention of trainers. 